\title{
Alejandro Panel (1699-1764) y la epigrafía hispana
}

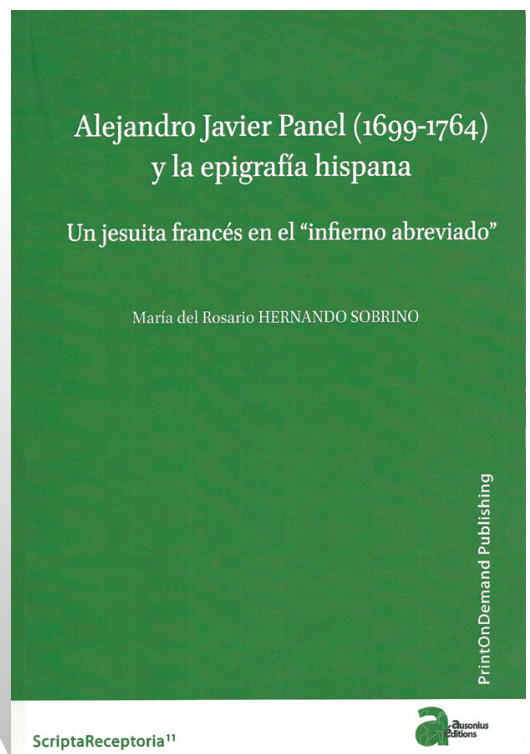

\section{FICHA BIBLIOGRÁFICA}

María del Rosario Hernando Sobrino, Alejandro Panel (1699-1764) y la epigrafía hispana. Un jesuita francés en el "infierno abreviado", Bordeaux, Ausonius Éditions, 2017 (Scripta Receptoria 11), 430 páginas. ISBN 978-2-35613-188-1

\section{Jesús Salas Álvarez I Universidad Complutense de Madrid}

Alejandro Javier Panel (1699-1777) Llegó en 1738 a España como preceptor de los Infantes, siendo designado en 1746 profesor del Colegio Imperial de Madrid, actividades que compaginará con su puesto de nombramiento como anticuario del Gabinete de Medallas de la Real Librería, hoy Biblioteca Nacional, que había sido creada por Felipe V en 1711, y en el que venía desempeñando sus funciones desde 1743. Por ese hecho siempre se le ha tenido en consideración por los investigadores españoles como uno de los principales eruditos en Numismática en el S. XVIII español.

Sin embargo, la Prof. Hernando Sobrino nos presenta una importante novedad a la biografía intelectual del Padre Panel, como son los estudios llevados a cabo por el jesuita francés sobre Epigrafía, a partir del análisis de sus manuscritos conservados en la Biblioteca Nacional, que hasta el momento presente habían pasado desapercibidos para numerosos investigadores y muy poco utilizados por el Corpus de Inscriptionum 
Latinarum II (CIL), pero que sin duda aportan importantes datos sobre los estudios epigráficos llevados a cabo en España en el S. XVIII.

La estructura del libro está organizada en 9 capítulos y 11 anexos. El capítulo 1 (pp. 13 63) está centrado en el papel desempeñado por la Epigrafía dentro de los estudios históricos de la primera mitad del S.XVIII, glosando el movimiento de los Novatores y de los primeros intentos realizados por Manuel Martí, el Deán de Alicante, y por Gregorio Mayans, o los proyectos institucionales llevados a cabo desde la Real Academia de la Historia. Con todos estos datos, la autora elabora una síntesis del período en cuestión que, hasta el momento presente, había sido tratado parcialmente por los estudios realizados sobre la Anticuaria y la Arqueología del XVIII.

El segundo capítulo (pp. 65-67) es una breve, pero necesaria, introducción al papel desempeñado por la Real Librería o Real Biblioteca, institución creada en 1711 por Felipe V, y en la que Alejandro Panel desempeñó gran parte de su labor como epigrafista y numísmata, ya en que 1743 fue designado para el cargo de Anticuario.

El tercer capítulo (pp. 69-79) es una biografía sobre el personaje, que como bien indica la autora era necesaria por los pocos datos que de él se conocían. En este apartado, hay que destacar la metodología empleada por la Dra. Hernando para acercarnos a Alejandro Panel, al utilizar no sólo información de los propios coetáneos sino también los de sus sucesores en el cargo de anticuario de la Real Librería, y más concretamente Basilio Sebastián Castellanos de Losada.

También es interesante el capítulo cuarto (pp. 81-95) que se centra en el análisis de la correspondencia mantenida por Alejandro Panel con otros eruditos contemporáneos (Marcos Burriel, Enrique Flórez, José Alsinet, Nicolás Estrada, Livino Leyrens, Francisco Pérez Bayer, Guillermo Tyrry, Pedro Leonardo de Villacevallos, Luis José Velázquez de Velasco y Bernardo de Estrada), todos ellos interesados en cuestiones de epigrafía y numismática, que participaron en mayor o menor medida en los proyectos institucionales llevados a cabo por los monarcas borbones e, incluso, alguno de ellos llegó a poseer una importante colección epigráfica.

Un hecho que analiza Rosario Hernando es la red de corresponsales reunida por el autor jesuita, y que fue una cuestión muy común entre los eruditos españoles del momento, como fue el caso de Enrique Flórez.

Una de las principales aportaciones de la obra la encontramos en el capítulo 5 (pp. 97 102), donde la autora hace una exhaustiva relación de los manuscritos de numismática (38 en total) y de epigrafía (en número de 10) que agrupan las obras de Alejandro Panel y que se conservan en la Biblioteca Nacional y en otras bibliotecas fuera de España.

El capítulo 6 (pp. 103-125) se centra en el análisis de los manuscritos relativos a la epigrafía latina hispana, en los que se distinguen tres grupos: "manuscritos primarios", que registran el simple vaciado de las fuentes bibliográficas; "manuscritos elaborados", auténticos corpora temáticos y, finalmente, los denominados "otros manuscritos" que, sin ser de contenido estrictamente epigráfico o referirse a otras provincias romanas, contienen alguna inscripción de Hispania.

Dos cuestiones pueden mencionarse de la lectura de este capítulo. En primer lugar, las similitudes que presentan los trabajos de A. Panel con los proyectos ilustrados de Luis José Velázquez de Velasco y Tomás Andrés de Gusseme, ambos amparados por la Real Aca- 
demia de la Historia, debido a la exhaustividad en la recopilación de las fuentes conocidas hasta el momento.

En segundo lugar, la Dra. Hernando ha podido recuperar la ficha-tipo empleada por Panel para diseccionar los manuscritos (pp. 115-117) y así poder elaborar sus trabajos, lo que supone una novedad respecto a trabajos anteriores sobre Historiografía de la Epigrafía española. Además, y ahondando un poco más en este sentido, podemos ver que este método no dista mucho del que un siglo después empleó E. Hübner para elaborar el Corpus Inscriptionum Latinarum.

El capítulo 7 (pp. 127-140) se centra en el estudio del método epigráfico empleado por Panel. Consistía en la creación de una serie de fichas que, posteriormente, se agrupaban en cuadernillos, divididos por poblaciones. Esta información era remitida a sus colaboradores, quienes sobre el terreno comprobaban la veracidad de los datos, realizando, en su caso, las correcciones pertinentes. Hemos de decir que este método de trabajo no era novedoso, pero si el habitual de la época, pues fue el mismo que aplicó el Padre Flórez para la redacción de su España Sagrada.

El Capítulo 8 (pp. 141-155) está dedicado a valorar el papel desempeñado por Alejandro Panel en la Historia de la Epigrafía Española, así como al uso que autores posteriores realizaron de los trabajos del autor jesuita. En especial, hay que destacar la escasa presencia que tienen sus manuscritos en el CIL, aun cuando hay casos, como la inscripción CIL II 3174, procedente de Rubielos de Mora (Toledo) - actualmente en paradero desconocido como bien señala Rosario Hernando- que aparece completa en el manuscrito de Panel, mientras que en la obra de Hübner está incompleta (p. 143).

El capítulo 9 (pp. 157-164) se centra en los «pioneros de la epigrafía latina hispana», donde la Dr. Hernando destaca la importancia de Alejandro Panel, a quien coloca al mismo nivel que Luis José Velázquez de Velasco, Marqués de Valdeflores. Igualmente, menciona las relaciones existentes entre ambos epigrafistas, que compartieron colaboradores y, sobre todo, su pertenencia a los mismos círculos políticos e instituciones culturales de la época.

No podemos finalizar este análisis sin hacer mención a los 11 anexos (pp. 185-430) presentes en la edición del trabajo, que constituyen una de las grandes aportaciones de la obra, no sólo porque facilitan la búsqueda de la información, sino también porque permiten realizar rápidamente interconexiones entre los diferentes apartados, lo cual redunda en una mayor importancia del propio trabajo, no sólo por su exhaustividad sino por su la sencillez a la hora de realizar cualquier consulta dentro del propio libro.

En definitiva, nos encontramos ante un libro que se va a convertir en obra de referencia por partida doble para los estudios de la epigrafía, de la Historia de la Epigrafía y de la Historia de la Arqueología. De una parte, por su análisis de la figura y obra de Alejandro Panel, y, por otra, porque servirá de modelo para futuras investigaciones sobre los estudios epigráficos llevados a cabo en España durante el S. XVIII. 